\title{
Clinical Uncertainty and Healthcare Disparities
}

Maxwell Gregg Bloche

Georgetown University Law Center, bloche@law.georgetown.edu

Ana I. Balsa

Harvard Medical School

Thomas G. McGuire

Harvard Medical School

Naomi Seiler

Johns Hopkins University

This paper can be downloaded free of charge from:

https://scholarship.law.georgetown.edu/facpub/344

29 Am. J.L. \& Med. 203-219 (2003)

This open-access article is brought to you by the Georgetown Law Library. Posted with permission of the author. Follow this and additional works at: https://scholarship.law.georgetown.edu/facpub

Part of the Health Law and Policy Commons 


\title{
GEORGETOWN LAW Faculty Publications
}

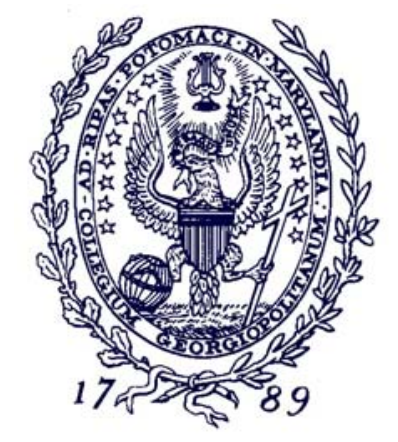

April 2010

\section{Clinical Uncertainty and Healthcare Disparities}

\author{
29 Am. J.L. \& Med. 203-219 (2003)
}

\section{Maxwell Gregg Bloche \\ Professor of Law \\ Georgetown University Law Center \\ bloche@law.georgetown.edu}

\section{Thomas G. McGuire}

Professor of Health Economics

Harvard Medical School

\author{
Ana I. Balsa \\ Center for Multicultural Mental Health Research \\ Cambridge Hospital Alliance \& \\ Harvard Medical School
}

\section{Naomi Seiler}

Bloomberg School of Public Health

Johns Hopkins University

This paper can be downloaded without charge from:

Scholarly Commons: http://scholarship.law.georgetown.edu/facpub/344/

Posted with permission of the author 


\title{
Clinical Uncertainty and Healthcare Disparities
}

\author{
Ana I. Balsa, Naomi Seiler, Thomas G. McGuire \& M. Gregg Bloche ${ }^{\dagger}$
}

\section{INTRODUCTION}

The Institute of Medicine Report, Unequal Treatment: Confronting Racial and Ethnic Disparities, affirms in its first finding: "Racial and ethnic disparities in healthcare exist and, because they are associated with worse outcomes in many cases, are unacceptable." "The mechanisms that generate racial and ethnic disparities in medical care operate at the levels of the healthcare system and the clinical encounter. Research demonstrates the role of healthcare system factors, including differences in insurance coverage and other determinants of healthcare access, in producing disparities. Research also shows, however, that even when insurance status and other measures of access are controlled for by statistical methods, racial and ethnic disparities persist. These disparities remain when researchers try by various methods to control for patients' clinical characteristics. Disparities are especially well documented through comparisons between white patients and African Americans and Latinos, but they are believed to affect other minority groups. As a result, many members of minority racial and ethnic groups receive less or inferior care. ${ }^{2}$ The purpose of this Article is to explore how one factor we regard to be key-provider and patient uncertainty about clinical decisions-contributes to disparities arising from the doctor-patient encounter.

$\dagger \quad$ Ana Balsa is a research associate at the Center for Multicultural Mental Health Research, Cambridge Hospital Alliance and Harvard Medical School. Naomi Seiler is a Fellow in Bioethics and Health Policy at the Johns Hopkins University, Bloomberg School of Public Health. Thomas G. McGuire is a professor of Health Economics at Harvard Medical School. M. Gregg Bloche is a professor of law at Georgetown University and an adjunct professor in the Dept. of Health Policy \& Management at the Johns Hopkins University, Bloomberg School of Public Health.

Research for this Article was partly supported by grant P01 MH59876 from the NIMH (Balsa and McGuire), a Greenwall Fellowship (Seiler) and a Robert Wood Johnson Investigator Award in Health Policy Research (Bloche). McGuire and Bloche were members of the Institute of Medicine Committee on Understanding and Eliminating Racial and Ethnic Disparities in Health Care.

1 Inst. Of Med., Unequal Treatment: Confronting RaCial and EThnic Disparities 160-79 (2002) [hereinafter UNEQUAL TREATMENT].

2 For a comprehensive review of these findings, see UNEQUAL TREATMENT, supra note 1. 
Uncertainty is a powerful force in medicine. Wennberg argues that uncertainty is the most important single influence on physician behavior. ${ }^{3}$ He divides clinical uncertainty into several categories-uncertainty about the nature of the patient's disease condition or health status, uncertainty about the effectiveness of a treatment even under ideal conditions and uncertainty about patient preferences and values. Arrow's cornerstone paper in health economics seeks to understand the medical care sector's special institutional characteristics and behavioral norms as social adaptations to clinical uncertainty. ${ }^{4}$ Uncertainty also pervades the legal and regulatory governance of the health sphere, undermining efforts to pursue fairness and efficiency through public policy. ${ }^{5}$

In what follows, we stress several roles for uncertainty as a contributor to healthcare disparities. First, uncertainty opens the way for myriad subjective influences on physicians' diagnostic and therapeutic assessments. The uncertainty of which we speak has a number of sources. These include ambiguity as to the diagnostic implications of clinical symptoms, signs and laboratory tests; incomplete information about the efficacy of diagnostic and therapeutic interventions; and unresolved differences of opinion about how to value potential clinical outcomes. These sources of uncertainty create wide space for clinical discretion. Subjective influences, including unfavorable stereotypes and attitudes about social groups, shape the exercise of this discretion. ${ }^{6}$

A second role for uncertainty has a very different character. Well-meaning clinicians, trying to act in their patients' best interests, look to gather as much information as they can, within time and resource constraints, concerning their patients' needs and interests, both biological and psychological. To do so, physicians must communicate with their patients-and listen closely to what patients have to say. If physicians, as a group, communicate less well with their minority patients than with Whites, greater uncertainty about minority patients' needs and interests results. This "uncertainty gap," we contend, can produce disparate treatment of patients from different racial and ethnic groups even in the absence of physician-held stereotypes or prejudice. Evidence suggests that such an uncertainty gap exists-that there is more "noise" in the communication "signal" when doctor and patient belong to different racial or ethnic groups with correspondingly different cultural patterns and styles.

Third, patients who are, if anything, even more uncertain about the value of medical interventions than are their doctors, ${ }^{7}$ make their own interactive assessments of the quality and reliability of their doctors' judgments. ${ }^{8}$ Patient uncertainty ensuing from "noise" in the communication "signal" between doctor and patient will reduce rationally-acting patients' reliance upon physician judgment; this, in turn, will yield reduced patient compliance with recommended treatment (and diminished

3 John E. Wennberg, On Patient Need. Equity, Supplier-Induced Demand, and the Need to Assess the Outcome of Common Medical Practices, 23 MED. CARE 512, 517 (1985).

4 Kenneth Arrow, Uncertainty and the Welfare Economics of Medical Care, 53 AM. ECON. REV. 941 (1963).

5 M. Gregg Bloche, The Invention of Health Law, 91 CAL. L. REV. (forthcoming 2003).

6 M. Gregg Bloche, Race and Discretion in American Medicine, 1 YALE J. HEALTH POL'Y L. \& ETHICS 95, 103-04 (2001).

7 Arrow, supra note 4, at 951 .

8 This interaction between doctor and patient can be modeled in game theory terms as a Nash equilibrium. See Ana Balsa \& Thomas McGuire, Prejudice, Clinical Uncertainty and Stereotypes as Sources of Health Disparities, 22 J. HEALTH ECON. 89, 102-03 (2003). 
inclination to seek medical consultation in the first place). Racial and ethnic disparities in the level of "noise" in this "signal" will thus produce disparities in patients' inclinations to seek out and rely upon medical advice. Perceptions or expectations by minority patients concerning white physicians' propensity toward racial and ethnic stereotypes and biases can be expected to widen these disparities in patient behavior.

In the next two sections, we expand on these arguments about the role of uncertainty in healthcare disparities, drawing, where possible, on the supporting evidence. It is likely, we argue, that the multiple ways by which uncertainty can generate disparities operate simultaneously in many clinical contexts. A crucial question from a legal and public policy perspective is whether and how the various organizational and financial arrangements associated with managed care operate to aggravate or reduce healthcare disparities. In the fourth section of this Article, we consider how some of these arrangements, including financial rewards for clinical frugality, affect the role of uncertainty in generating healthcare disparities.

\section{CLINICAL UNCERTAINTY, DISCRETION \& BIAS}

\section{A. Clinical Uncertainty}

"Some questions cannot be answered no matter how diligently one searches the literature, no matter which expert one consults. ",9

For all its advances, the practice of modern medicine involves a great deal of scientific uncertainty and therefore involves a great deal of discretion on the part of doctors and other clinicians. ${ }^{10}$ Healthcare providers operate at best within what Simon termed "bounded rationality" "-reasoned decision-making based on fullyinformed assessment of all possible contingencies is beyond health professionals' reach. The call for development of "evidence-based medicine" reflects the limits of the science base upon which current clinical practice is founded. In many-perhaps most-medical situations, clinicians lack the systematic health outcomes data necessary to compare, in scientific fashion, the expected efficacy of diagnostic and therapeutic alternatives. ${ }^{12}$ Neither health insurance contracts nor ethical and legal rules do a great deal to narrow the resulting clinical discretion. ${ }^{13}$ Contractual language in private health plans does not set clear limits. Insurance contracts typically require that a plan provide coverage for "medically necessary" services, subject only to provider network restrictions and to the requirement that care not be "investigational" or "experimental." The opaque term "medical necessity" is not defined in health plan contracts; it therefore must be subject to the interpretation of providers and utilization managers. Medicare and Medicaid are similarly nondirective about providers' decisions; the statutory language establishing both programs requires coverage when "medical necessity" is present. Incorporation of

\footnotetext{
9 Dean Gianakos, Accepting Limits, 158 ARChIVES INTERNAL MED. 1059, 1059 (1998).

10 See John E. Wennberg, Understanding Geographical Variations in Healthcare Delivery, 340 NEW ENG. J. MED. 52 (1999).

11 See Herbert A. Simon, Models of Bounded Rationality: BEHAVIORAL ECONOMICS AND BUSINESS ORGANIZATION 206-07 (1982).

12 Steven H. Woolf, The Need for Perspective in Evidence-Based Medicine, 282 JAMA 2358, 2359 (1999).

13 Bloche, supra note 5.
} 
detailed clinical practice protocols into health insurance contracts (and the regulations that govern public programs) could in theory constrain providers' discretion. But, this rule-based approach encounters serious practical obstacles. Uncertainty about the efficacy of many diagnostic and therapeutic alternatives makes it impossible to base comprehensive clinical practice protocols entirely, or even largely, on science. This makes use of such protocols easy to challenge and difficult to defend. Moreover, uncertainty and subjectivity in the assessment of particular patients' conditions leave much space for discretion when doctors decide which practice protocols to apply. ${ }^{14}$

Medical ethics, in theory, could constrain healthcare providers' discretionary judgment, but the evolution of ethical theory has not taken such a course. The Hippocratic ethical tradition emphasizes physicians' loyalty (to patients), good intentions and commitment to learning and good craftsmanship, but it does not set forth principles or rules to channel clinical discretion. The contemporary bioethics movement's emphasis on patient autonomy entails an effort to keep provider discretion within the bounds of respect for patient preferences, but providers have broad scope for discretion in their presentation of risks, benefits and alternatives to their patients. Likewise, medical tort law's approach to the setting of legal standards of care defers to physicians' practice norms as sources of standards. ${ }^{\text {S }}$ The U.S. Supreme Court's recent decision in Rush Prudential HMO, Inc. v. Moran ${ }^{16}$ extended this deferential approach to the law governing health insurers' coverage denials in most states. The Court characterized state-mandated independent review of insurers' "medical necessity" determinations as akin to a medical "second opinion"17 and thus a matter of professional judgment. By deferring to physicians' practice norms and professional judgment, medical malpractice and insurance law allow for a wide scope of physician discretion.

Treatment of prostate cancer illustrates the uncertainties that providers and patients routinely face. The American Urological Association and the American College of Physicians hold that radical prostatectomy, radiation therapy and watching and waiting without intervention are all valid treatment options because there is insufficient evidence to establish that any one of these approaches is better than the others. ${ }^{18}$ Empirical studies have yielded conflicting results, and countries with similar prostate cancer mortality rates have very different standard treatments. ${ }^{19}$ On the other hand, particular surgeons have individualized, sharply differing views about the value of surgery versus other approaches. Uncertainty, along with consequent lack of agreement on a single, standard treatment, leaves room for individual doctors with varying views to advise their patients in differing ways without acting contrary to established, evidence-based practice. Similar uncertainty persists in many areas of medical practice, engendering wide variation in medical practice norms within and across different regions of the United States. ${ }^{20}$

\footnotetext{
$14 \quad I d$.

$15 \quad l d$.

16536 U.S. 355 (2002).

17 Id. More than forty states now have laws requiring independent medical review of insurers' coverage denials when patients or doctors request such review.

18 Timothy J. Wilt, Uncertainty in Prostate Cancer Care: The Physician's Role in Clearing the Confusion, 283 JAMA 3258, 3259 (2000).

19 Id. at 3258.

20 See. e.g., Wennberg, supra note 10. New technologies expand treatment possibilities but can also increase uncertainty. Welch et al. outline four sources of uncertainty that clinicians face in
} 
Physician discretion influences the care that patients receive even when ample evidence bears on the comparative efficacy of clinical alternatives. A doctor's knowledge and skills, past experience, perceptions of her patients' values and preferences, and financial and other personal incentives are among the factors that shape physician judgment. Empirical studies confirm the importance of these factors, even when scientific evidence for and against particular therapies is strong. ${ }^{21}$ Much of the variation in what happens to patients - in how their evaluation and treatment is managed-is associated with clinical discretion. Evidence for racial and ethnic disparities in healthcare is essentially a demonstration that such variation systematically correlates with the race and ethnicity of patients.

\section{B. Heuristics, Stereotypes \& Bias}

Clinical discretion is an inevitable feature of medical practice under conditions of scientific uncertainty, bounded human rationality and variation in personal motivations and preferences. As such, discretion is not inherently negative. It is, however, a necessary condition for the indulgence of stereotypes and biases by physicians in a manner that engenders racial and ethnic disparities. If a patient's clinical situation were unambiguous and if a single, scientifically-proven "best practice" were the only professionally acceptable clinical response to this situation, then a physician who failed to follow this "best practice" would be acting unethically. This "no choice" circumstance is not common. John Eisenberg has observed that clinical uncertainty creates a portal for the entry of other physician motives, such as pursuit of income or status. When obstetricians adapt to fee changes by persuading higher proportions of pregnant women to have Cesarean sections, the doctors are exercising discretion in self-interested fashion, ${ }^{22}$ though they may not be conscious of a causal connection between their decisions and their financial incentives. By analogy, racial and ethnic stereotypes and biases, whether conscious or unconscious, can shape the exercise of discretion in systematic fashion and result in disparities. ${ }^{23}$

One way to contend with uncertainty is to employ heuristics-decision rules that have a reasonable (but not rigorous) basis and that work much of the time. For example, a provider may adhere to a rule holding that a pregnant patient who experiences nausea probably has morning sickness. This is not always true, but is a good basis for proceeding. An extensive literature in psychology and related fields documents ways by which people rely on heuristics as tools of judgment. Heuristics are, in essence, mental "shortcuts" that simplify decision-making. Physicians are particularly likely to rely on heuristics because they work under conditions of high

\footnotetext{
counseling patients about the results of clinical genetic tests: (1) uncertainty about who will develop the disease (because most genes have incomplete penetrance, meaning they will not result in disease in all carriers); (2) uncertainty about the extent to which the risk has been overstated (because some studies of genetic determinants of disease thus far have studied disproportionately high-risk populations); (3) uncertainty as to the right time to learn the information (because genetic markers may be detected decades before the manifestation of a disease); and (4) uncertainty about the benefits of early intervention. H. Gilbert Welch et al., Uncertainties in Genetic Testing for Chronic Disease, 280 JAMA 1525, 1525-26 (1998).

21 Joseph P. NEWHOUSE \& THE INSURANCE EXPERIMENT Group, FreE FOR ALL? LESSONS FROM THE RAND HEALTH INSURANCE EXPERIMENT (1993).

22 J. Gruber \& M. Owings, Physician Financial Incentives and Cesarean Section Delivery, 27 RAND J. ECON. 99, 100 (1996).

23 Bloche, supra note 6, at 104.
} 
cognitive demand, enormous complexity and extreme time pressure. ${ }^{24}$ The average physician visit in outpatient settings lasts twenty minutes. ${ }^{25}$

When applied to groups of people, heuristics can be invidious. They can take the form of "stereotypes" based on easily ascertainable characteristics, such as age, sex or race. ${ }^{26}$ The boundary between a useful "heuristic" and a problematic "stereotype" is fuzzy. Is the generalization "men are uncomfortable talking about their feelings and better off being treated by drugs for their depression" a useful rule of thumb for a therapist, or a stereotype inhibiting appropriate matching of patients to treatment? For the purposes of this Article, we define stereotypes as unwarranted commitments, both conscious and unconscious, to generalizations about social groups-generalizations that result in unfavorable judgments and actions. For example, the generalization, "black patients are less cooperative with treatment than are white patients" may dissuade a provider from recommending a difficult but effective course of treatment to a black patient. Indeed, research has shown that doctors believe African Americans are more likely than white patients to engage in behavior destructive to their health and less likely to comply with treatment. ${ }^{27}$

In addition to stereotypes, some physicians might simply be biased against members of racial or ethnic minority groups. In social psychology, bias (or prejudice) is defined as a negative attitude or affect, ${ }^{28}$ a phenomenon distinct from stereotypic or heuristic cognition. This is, to some degree, an oversimplification: considerable evidence indicates that emotion influences cognitive processes. ${ }^{29}$ The IOM Report notes "there is no evidence that any significant proportion of healthcare professionals in the United States harbors overtly prejudicial attitudes." ${ }^{30}$ However, the IOM Report later acknowledges that "healthcare providers, like other members of society, may not recognize manifestations of prejudice in their own behavior.",31 Physician bias or prejudice is one of the most common explanations offered for healthcare disparities. Studies have made it clear that providers are not immune to racial bias. In one experiment, a group of mental health clinicians was "primed" with words related to African American stereotypes (e.g., "blacks," "Negroes," "rhythm") flashed on a computer screen for eighty milliseconds, while another group was primed with neutral words (e.g., "things," "about," "water"). ${ }^{32}$ The former group rated hypothetical African American patients significantly more negatively along several scales of hostility-related attributes than did the latter group. Although the stereotypic terms used were not all blatantly negative, they encouraged providers to impute negative traits to African Americans.

\footnotetext{
24 UNEQUAL TREATMENT, supra note 1, at 161.

25 David Mechanic et al., Are Patients' Office Visits with Physicians Getting Shorter?, 344 NEW ENG. J. MED. 198, 198 (2001).

26 John F. Dovidio, Stereotyping, in THE MIT ENCYClopedia of THE Cognitive SCIENCES (Wilson \& Keil eds., 1999).

27 M. Van Ryn \& J. Burke, The Effect of Patient Race and Socio-Economic Status on Physicians' Perceptions of Patients, 50 SOC. SCI. \& MED. 813 (2000).

28 Susan T. Fiske, Stereotyping. Prejudice and Discrimination, in THE HANDBOOK OF SOCIAL PSYCHOLOGY 357-411 (Daniel T. Gilbert et al. eds., 4th ed. 1998).

29 George Loewenstein et al., Risk as Feelings, 127 PSYCH. BULLetin 267, 267 (2001).

30 UNEQUAL TREATMENT, supra note 1 , at 166.

$31 \quad$ Id. at 162.

32 José M. Abreu, Conscious and Nonconscious African-American Stereotypes: Impact on First Impression and Diagnostic Ratings by Therapists, 67 J. CONSULTING \& CLINICAL PSYCH. 387 (1999).
} 
Studies of clinicians' responses to patients of different races have found that white and minority providers-and male and female clinicians-differ significantly in these responses. In one study, for example, a group of medical students viewed a video of either a black female or white male "patient" (an actor) with the same symptoms. Minority and female students saw the patients as having similar qualities of life, but white and male students (and the group as a whole) perceived the black female's quality of life as lower. ${ }^{33}$

Though experimental in design, these studies support the idea that providers' subconscious stereotypes and biases affect the way they treat patients. Opportunities for involvement of provider biases and stereotypes arise at both the diagnostic and treatment stages. When assessing a minority patient's condition, for example, a provider may incorporate assumptions about the individual's lifestyle or risk-taking behaviors. When developing a treatment regimen, a provider may draw upon stereotypes about therapeutic compliance and family support-or judgments about the import of quality-of-life considerations.

The evidence linking bias and stereotyping to healthcare disparities is circumstantial. There are studies that present evidence for bias and stereotyping, and there are many studies showing that providers treat minority patients differently than white patients. Missing from this picture are studies that establish a causal link between stereotypes and bias and real world disparities in clinical practice. Creative research strategies that explore this probable, but not clearly established, link are much needed.

\section{III. “STATISTICAL” DISCRIMINATION \& HEALTHCARE DISPARITIES}

\section{A. THE Role OF THE PROVIDER}

Even in the absence of physician racial or ethnic bias, clinical uncertainty can lead to healthcare disparities. In the process of diagnosing and recommending treatment, healthcare providers must reach judgments about patients' conditions and reactions to treatment without complete, accurate information. Moreover, they often must do so under severe time pressures and resource constraints. These informational inadequacies result in pervasive uncertainty about individual patients' clinical situations. To cope with this uncertainty, doctors supplement the information gained from evaluating a patient with ideas (accurate or otherwise) about the overall prevalence of the disease and/or the expected benefits from treatment among social groups to which the patient belongs. These ideas are learned in medical school, absorbed from mentors in the course of clinical training and drawn from both the medical literature and personal experience. This psychological process can be modeled as rational, Bayesian inference in response to clinical uncertainty; indeed, the normative literature on clinical decision-making urges physicians to reason in this fashion. ${ }^{34}$ Bayesian decision-making, however, can cause racial, ethnic and other inter-group healthcare disparities even when there is no systematic physician bias against any racial or other social group. Inter-group disparities that arise in this fashion, exclusively from uncertainty, have been denoted in the economics literature as "statistical discrimination."

33 Saif S. Rathore et al., The Effects of Patient Sex and Race on Medical Students ' Ratings of Quality of Life, 108 AM. J. MED. 561 (2000).

34 Milton C. Weinstein et al., Clinical Decision Analysis (1980). 
Statistical discrimination employs conditional probability rules to meld prior beliefs about prevalence of the disease or treatment effectiveness and newly gathered information about particular patients. The doctor's degree of uncertainty about each patient's condition determines the relative weights she will place on her prior beliefs versus the symptoms and other signals she perceives from the patient. If the provider had absolute confidence in the quality and completeness of her clinical information about the patient, she would consider only this information in her decision-making and place no weight upon her prior beliefs about disease prevalence and expected clinical benefits among different social groups. But, most decisions in actual practice have to be made in the absence of solid evidence as to the efficacy of diagnostic and therapeutic measures and in the absence of complete understanding of the patient's symptoms. To make better informed-decisions, the Bayesian model holds, providers resort to priors or heuristics about the pathophysiology of disease, its prevalence and the efficacy of treatments across social categories. Consider age and hypertension as an example. Older patients are more likely to be hypertensive than younger patients. ${ }^{35}$ After taking a blood pressure reading, a doctor may be more likely to discount a young person's reading as due to nervousness than an older person's. The same reading (signal) would be less likely to lead to a diagnosis for a patient when the prior probability is low. Heuristics and signals generated by patients and received by doctors are fundamental to understanding the relationship between clinical uncertainty and racial and ethnic healthcare disparities, even absent doctors' prejudice.

Another model of statistical discrimination looks to communication problems that may be greater, in the aggregate, between minority patients and doctors. ${ }^{36}$ Expression of pain symptoms, for example, differs among cultural and racial groups $^{37}$ and doctors, who are disproportionately white and may be less prepared to understand minority patients' reports of pain. Different perceptions of similar signals emitted by patients of different ethnic or racial groups, due to language or cultural differences between patient and doctor, can lead doctors to make different decisions about diagnoses and treatments. These differences may occur even when the doctor has the same regard for each patient (no bias or prejudice) and holds to the same heuristics about prevalence and benefits from treatment for members of different ethnic or racial groups. The higher the cultural and language barriers when doctor and patient encounter each other, the lower the doctor's reliance on the signals emitted by the patient, this model holds. In other words, since the weight placed by the doctor on the clinical information gleaned from each patient depends on the quality of this information (as understood by the doctor), poorer communication between doctors and minority patients will lead doctors to depend less on symptoms and other individualized clinical information and more on heuristics when deciding on diagnosis and treatment. ${ }^{38}$

35 V. Benson \& M.A. Marano, Current Estimates from the National Health Interview Survey, 1995, 10 ViTAL \& Health STATS. 1 (1999).

36 Ana Balsa \& Thomas McGuire, Statistical Discrimination in Health Care, 20 J. HEALTH ECON. 882 (2001).

37 Vence L. Bonham, Race, Ethnicity, and Pain Treatment: Striving to Understand the Causes and Solutions to the Disparities in Pain Treatment, 29 J.L. MED. \& ETHICS 52, 52 (2001).

38 Uncertainty arising from provider-patient communication may be particularly problematic in mental healthcare, where a relatively large portion of information is gained in the provider-patient exchange. Ana Balsa et al., Testing for Statistical Discrimination: An Application to Health Care Disparities (2002), available at http://www.hcp.med.harvard.edu/people/faculty/mcguire.html. This has an important implication for the effort to achieve parity between mental health and other medical 
Barriers to communication arise not just as a consequence of racial dissimilarities between physicians and patients, but also arise from a lack of familiarity with a community. Black doctors have higher proportions of black patients than do white doctors, and Latino doctors see higher proportions of Latino patients. ${ }^{39}$ Whether this is due to physician choice, patient choice, systemic factors or all three factors, the result is that minority providers may be better able than white providers to communicate effectively with minority populations due not only to personal background, but also to professional experience. When language and cultural barriers produce systemic racial or ethnic differences in physician uncertainty about individual patients' clinical conditions, several implications ensue, even absent racial or ethnic bias on the part of physicians. First, racial and ethnic disparities in the provision of healthcare are not necessarily a matter of providing less care to disadvantaged groups. Higher uncertainty ensuing from poorer communication can also lead to disparities whereby disadvantaged groups get "more" healthcare than Whites. For example, uncertainty about psychiatric patients' dangerousness to other people might lead clinicians to more frequently hospitalize black patients who might be psychotic. ${ }^{40}$ However, greater clinical uncertainty always means that on average, minorities are less well off than Whites as the result of the clinical encounter, ${ }^{41}$ an important implication of the statistical discrimination model. Because of poorer communication, doctors are less able to match patient needs to adequate treatment. Health outcomes and results from treatment will usually be poorer for minorities-a result that remains true whether minorities are getting more or less care than Whites. ${ }^{42}$

Clinical uncertainty can also yield disparities linked to doctors' heuristics concerning the likelihood that members of different racial or ethnic groups will carry a disease or will benefit from treatment. For instance, a doctor may believe that the underlying distribution of severity differs across races, and hence may be willing to use the "category" race as an aid to improve his diagnosis when drawing an inference about the severity of a patient's condition. Genetic differences between individuals of different races are minor in most cases. But, illnesses and their treatments are shaped by social and cultural factors as well as biological determinants. Hypertension is more prevalent in African Americans than Whites. ${ }^{43}$ Some anti-depressant drugs are metabolized more slowly by Blacks than Whites and should therefore be administered in lower doses. ${ }^{44}$ Rational profiling, or reliance on scientifically valid heuristics across racial and ethnic groups, is potentially efficient

insurance coverage: provider payment schemes and institutional arrangements that fail to address obstacles to provider-patient communication may engender especially wide racial and ethnic disparities in mental healthcare.

39 Miriam Komaromy et al., The Role of Black and Hispanic Physicians in Providing Health Care for Underserved Populations, 334 NEW ENG. J. MED. 1305 (1996); Ernest Moy \& Barbara A. Bartman, Physician Race and Care of Minority and Medically Indigent Patients, 273 JAMA 1515 (1995).

40 N. Breaux \& D. Ryujin, Use of Mental Health Services by Ethnically Diverse Groups Within the United States, 52 CLINICAL PSYCH. 4 (1999); Lonnie R. Snowden, African American Service Use for Mental Health Problems, 27 J. CMTY. PSYCH. 303 (1999).

4l Balsa \& McGuire, supra note 36.

42 Exactly the same conclusions apply when poor interpretations of symptoms result from the application of screening instruments that are not culturally valid for certain populations.

43 Benson \& Marano, supra note 35.

44 K.M. Lin et al., The Use of Psychotropic Medications in Working with Asian Patients, in WORKING WITH ASIAN AMERICANS: A GUIDE FOR CLINICIANS (1997). 
because the use of all available, valid information optimizes the average outcomes for patients in all groups. ${ }^{45}$ While rational profiling can explain certain types of disparities, its potential as an explanation of lower aggregate rates of use of care by minorities is dubious. If minorities are in general sicker than Whites, ${ }^{46}$ the use of these priors should lead doctors to recommend more care overall for minorities, not less. $^{47}$

As noted supra, the application of heuristics as an aid to decision-making under uncertainty can also have negative consequences when the "priors" used are inaccurate and negative (stereotypical), even in the absence of bias, conscious or otherwise, on the part of the doctor. Moreover, some heuristics that are initially inaccurate can be rendered self-fulfilling by physicians' actions and patients' reactions. $^{48}$

\section{B. The Role of the Patient}

Racial and ethnic minority patients' responses to healthcare providers are another potential source of disparities. Some patient behavior associated with disparities, such as lower rates of compliance, might be a rational response to patients' perceptions of their likelihood of gain from medical care. Patients experience costs of seeking care and of complying with care. If they are acting rationally, they only find it worthwhile to demand care when such costs do not exceed the expected benefits. Patients' mistrust, uncertainty about the effectiveness of treatment or experiences of discrimination in other life settings will lower the expected value of care from the patient's point of view. This lower expected benefit will translate into a lower likelihood of seeking care and following healthcare providers' instructions. Although research on this question is not extensive, some studies suggest that African Americans refuse invasive procedures at higher rates than Whites. ${ }^{49}$

Problems of communication between doctors and minority patients, due to language or cultural barriers, are likely to lower minorities' rational expectations about the value of care and to thereby shrink demand. Rational patients will be aware that miscommunication at the clinical encounter increases clinical uncertainty and decreases the value of the match between health needs and treatment. They are therefore likely to respond to those expectations by using healthcare services at

45 Balsa \& McGuire, supra note 8.

46 U.S. Dep'T of Health \& Human Servs., Healthy PeOPle 2010 (2000); Nat'l inst. of Health, Strategic Research Plan to Reduce and Ultimately Eliminate Health DISPARITIES, FISCAL YEARS 2002-2006 (draft, Oct. 6, 2000).

47 In some cases, though, higher severity may lead to less appropriateness of use of a certain procedure. The presence of many co-morbidities reduces the likelihood of late angiography on patients with acute myocardial infarction. Balsa \& Guadagnoli (2003) (untitled, unpublished manuscript, Harvard Medical School, on file with author).

48 Even if the prevalence or outcome statistics on which a provider relies are accurate, these adjustments might contribute to clinically irrational disparities in health status. Bowser argues that providers' reliance on differential prevalence (and outcome) data for different ethnic groups creates a sense of "these people just don't do well" that contributes to continued under-treatment or undervaluation of minority patients' well-being. Rene Bowser, Racial Bias in Medical Treatment, 105 DICK. L. REV. 365 (2001).

49 Allison D. Schecter et al., Influence of Gender, Race and Education on Patient Preferences and Receipt of Cardiac Catheterizations Among Coronary Care Unit Patients, 78 AM. J. CARDIOLOGY 996 (1996); Steven P. Sedlis et al., Racial Differences in Performance of Invasive Cardiac Procedures in a Department of Veterans' Affairs Medical Center, 50 J. CLINICAL EPIDEMIOLogy 899 (1997). 
lower rates-by not seeking care or by delaying care. Or, they may fail to comply with recommended care after they initiate contact with a provider by missing followup appointments, declining to undergo surgery or not taking prescribed medications. ${ }^{50}$ It is worth stressing that these different behaviors by members of different racial and ethnic groups need not stem from different underlying "preferences" about healthcare, but simply from different perceptions of the costs and benefits of participation in the healthcare system. In other words, the gap in healthcare use that is caused by problems of communication between doctor and patient can be widened by patients' anticipation of such problems. In line with this idea, some studies examining the benefits of ethnic matches conclude that patients who are treated by physicians of the same race or ethnicity express higher satisfaction with their care, ${ }^{51}$ obtain more preventive care, ${ }^{52}$ remain in treatment longer $^{53}$ and report better physical functioning. ${ }^{54}$ However, the literature is not unanimous on the benefits of ethnic matching for minority patients. ${ }^{55}$ We also note that overt use of race or ethnicity by healthcare institutions as a criterion for matching doctors and patients would raise troubling moral and legal questions.

Uncertainty about the benefits of healthcare may, moreover, potentiate patientheld stereotypes. Negative heuristics about healthcare providers are likely to be held by racial and ethnic group members who either experienced discrimination in the past or come from cultures with different approaches to organization and provision of healthcare services. Beliefs such as "doctors do not spend enough time with minority patients" or "doctors experiment with minorities" can result from histories of discrimination and from migrants' prior experiences with other systems of care. When patients have had little exposure to a health system, differences between what they expect from care and what care really provides can be large. Because learning through trial and error about the existence and quality of services can be very costly in healthcare, these gaps in expectations are likely to discourage use, particularly when social networks are poor. If many of these heuristic beliefs are generated "outside" the healthcare system, they will be difficult to change through healthcarespecific policies.

Finally, patients' uncertainty and demand for healthcare services may engender a vicious circle. The lower demand that ensues from higher uncertainty results in less exposure to the system and less knowledge about how the system works. This generates even more uncertainty and doubt on the part of patients. Their search costs become even higher. The downward spiral is made worse by poor social

50 R.C. Kessler et al., The 12-Month Prevalence and Correlates of Serious Mental Illness (SMI), in Mental Health, United STATES (R.W. Manderschield \& M.A. Sonnenschein eds., HHS, Pub. No. (SMA) 96-3098, 1996); Amy Y. Zhang et al., Differences Between Asian and White Americans' Help Seeking and Utilization Patterns in the Los Angeles Area, 26 J. CMTY. PSYCH. 317 (1998).

51 Lisa Cooper-Patrick et al., Race, Gender and Partnership in the Patient-Physician Relationship, 282 JAMA 583 (1999).

52 Somnath Saha et al., Patient-Physician Concordance and the Perceived Quality and Use of Health Care, 159 ARCHIVES INTERNAL MED. 997 (1999).

53 Stanley Sue et al., Community Mental Health Services for Ethnic Minority Groups: A Test of the Cultural Responsiveness Hypothesis, 59 J. CONSUlTING \& CLINICAL PSYCHOLOGY 533 (1991); David T. Takeuchi et al., Return Rates and Outcomes from Ethnicity-Specific Mental Health Programs in Los Angeles, 85 AM. J. PUB. HEALTH 638 (1995).

54 Eliseo J. Pérez-Stable et al., The Effects of Ethnicity and Language on Medical Outcomes of Patients with Hypertension or Diabetes, 35 MED. CARE 1212 (1997).

55 J. Chen et al., Racial Differences in the Use of Cardiac Catheterization After Acute Myocardial Infarction, 344 NEw ENG. J. MED. 1443 (2001). 
networks, in the case of recent immigrants, for example, and by social networks that share poor exposure to the healthcare system.

\section{DOES MANAGED CARE EXACERBATE OR AMELIORATE HEALTHCARE DISPARITIES STEMMING FROM CLINICAL UNCERTAINTY?}

In the last decade, many studies have analyzed the impact of managed care on access to health services and quality of care. While some studies point to an improvement in access, others suggest that managed care gives rise to large cutbacks in mental health and other services. ${ }^{56}$ The question of whether managed care has different impacts for different racial and ethnic groups on access to health services and quality of care has been studied more recently, and answers have varied. Using the 1996 Medical Expenditure Panel Survey, de Laet et al. found that managed care organizations substantially narrowed racial and ethnic gaps in preventive healthcare. In particular, Hispanics in managed care were more likely than their fee-for-service counterparts to report use of preventive services. ${ }^{57}$ But, other studies suggest that the penetration of managed care has exacerbated differences in healthcare use between Whites and minorities. ${ }^{58}$ These studies offer few insights into how managed care might either widen or reduce racial and ethnic disparities. In this Section, we highlight factors inherent in managed care that may contribute to clinical uncertainty, setting the stage for wider disparities. We also examine features of managed care that might draw minority group members into the healthcare system and thereby reduce racial and ethnic disparities. We focus on two central themes in managed care: cost-containment strategies and financial incentives to enroll patients.

\section{A. COST-CONTAINMENT}

Many managed care organizations use practice guidelines and utilization review to control the quality and costs of the services their providers supply. Whether these approaches ameliorate disparities by reducing variation in clinical practice patterns and thereby shrinking the space for discretion, or whether they contribute to disparities by making effective advocacy more important as a determinant of the intensity and quality of care is unclear. To the extent that health plans rely on centralized utilization management to control costs, robust advocacy by patients and physicians vis-a-vis health plan bureaucracies becomes more important as a factor in the care obtained.

56 Richard G. Frank \& Thomas G. McGuire, Savings from a Medicaid Carve-Out for Mental Health and Substance Abuse Services in Massachusetts, 48 PSYCH. SERVS. 1147 (1997); William Goldman et al., Cost and Use of Mental Health Services Before and After Managed Care, 17 HEALTH AFFAIRS 40 (1998).

57 David E. de Laet et al., Receipt of Preventive Services Among Privately Insured Minorities in Managed Care Versus Fee-for-Service Insurance Plans, 17 J. GEN. INTERNAL MED. 451 (2002). For a similar argument, see Jennifer S. Haas et al., Effect of Managed Care Insurance on the Use of Preventive Care for Specific Ethnic Groups in the United States, 40 MED. CARE 743 (2002).

58 Eric C. Schneider et al., Racial Disparities in the Quality of Care for Enrollees in Medicare Managed Care, 287 JAMA 1288 (2002); Ming Tai-Seale et al., Racial Disparities in Service Use Among Medicaid Beneficiaries After Mandatory Enrollment in Managed Care: A Difference in Differences Approach, 38 INQUIRY 49 (2001). 
While clinical practice protocols and centralized utilization management potentially restrict clinical discretion, the subjectivity and ambiguity of clinical situations makes it exceedingly difficult to standardize clinical practice; moreover, bounded human rationality makes it impossible to develop practice guidelines for all contingencies. $^{59}$ Utilization reviewers must, in many cases, make coverage decisions under conditions of ambiguity and uncertainty. They thus exercise considerable discretion in their own right. The interaction between utilization reviewers' and bedside clinicians' discretionary judgments-and the implications of this interaction for racial and ethnic disparities in healthcare-merit further study. We wish to highlight two phenomena that may contribute to disparities: (1) because utilization reviewers are no less influenced by stereotypes and bias than are physicians, their coverage decisions in cases marked by uncertainty may vary with race and ethnicity, and (2) clinicians' less robust advocacy on behalf of minority patients may work in dismal synergy with utilization reviewers' stereotypes and biases, widening disparities beyond those that would ensue from bedside clinical discretion by itself.

Managed care's navigational challenges for patients merit further consideration. A patient's receipt of more intensive or higher quality treatment may depend on her physician's vigorous advocacy within a managed healthcare system. To the extent that minority patients experience more cultural distance and disempowerment when negotiating managed care bureaucracies than do their white counterparts, they may assert their needs less effectively and obtain poorer results. ${ }^{60}$ Moreover, the vigor of a physician's advocacy efforts is likely to reflect the extent to which the doctor empathizes with a patient and otherwise values access to the services at issue. Doctors influenced by negative stereotypes and biases, or who simply do not understand their patients' expression of symptoms, perspectives and values may be less likely to advocate vigorously on their patients' behalf and less likely to recommend treatments that might require such advocacy.

Another cost-control strategy employed by managed health plans is selection of limited panels of providers. By so doing, health plans can both screen out high-cost physicians and employ their bargaining power in concentrated fashion to encourage the providers they select to practice frugally. Health plans routinely monitor physicians' clinical practice patterns. Moreover, capitation-based methods of paying providers reward doctors for accepting higher numbers of patients and minimizing the time they spend with each. Health plans' criteria for selecting providers and financial pressures to practice frugally may (1) increase levels of uncertainty in

59 Bloche, supra note 6.

60 No published studies in the health services research literature test this hypothesis, but effects along these lines have been observed in comparative studies of White and minority performance in mediation of legal disputes. See Ellen Waldman, Substituting Needs for Rights in Mediation: Therapeutic or Disabling?, 5 PSYCH. PUB. POL'Y \& L. 1103 (1999) (analyzing unpublished study results indicating that Latino and African American litigants report greater subjective satisfaction but achieve poorer economic results in mediation of small claims court disputes). A recent study of the frequency of patients' complaints to health plans lends circumstantial support to the hypothesis. A nation-wide survey of more than 1200 adults covered by insurers other than Medicare found that Blacks and Asian Americans were about half as likely as Whites to complain to their health plans. Mark Schlesinger et al., Voices Unheard: Barriers to Expressing Dissatisfaction to Health Plans, 80 Milbank Quarterly 709, 722, 733 (2002) (reporting findings from the 1999 Kaiser Family Foundation National Survey on Consumer Experiences with Health Plans). This report was not accompanied by information on the extent to which these complaints arose during patients' efforts to negotiate managed care bureaucracies in order to obtain health services. 
doctor-patient communication and (2) encourage doctors to exercise clinical discretion in ways that disadvantage some racial and ethnic groups.

The screening out of more costly providers risks excluding those clinicians who are most likely to put in additional time and effort with minority patients to better understand their symptoms and needs. To the extent that this occurs, the resulting impairment of doctor-patient communication contributes to clinical uncertainty. It may thereby widen racial and ethnic disparities via the mechanisms described above. Moreover, organizational and financial pressures to practice frugally encourage clinicians to look for places to cut back on costly treatments and referrals. Physicians' stereotypes, biases and greater uncertainty about the needs of minority patients put these patients at risk for bearing a disproportionate share of the costcontrol burden. Time and financial pressures on the exercise of clinical discretion lead to greater reliance on stereotypes and biases. Beyond this, physicians' expectations about who may be more likely to protest, or even to sue, over withholding of services are likely to influence their judgments about when to cut back on costly care. To the extent that physicians believe, accurately or otherwise, that members of disadvantaged racial and ethnic groups are less likely to protest or to sue, physicians may be more inclined to withhold services from such patients than from Whites with similar clinical presentations. ${ }^{61}$

Finally, pressures to reduce referrals to specialists are likely to increase clinical caretakers' uncertainty about their patients' symptoms and needs by pushing caretakers to make decisions beyond the bounds of their greatest technical

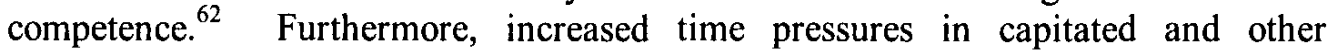
managed care systems discourage physicians from taking time to stay current on medical literature and to research the literature bearing on particular patients' conditions.

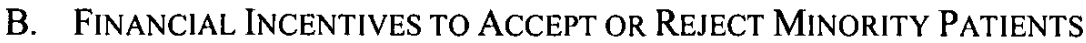

Health plans and providers have conflicting incentives to seek and to avoid minority patients. On the one hand, minority patients are, on average, sicker than white patients ${ }^{63}$ and, in the absence of adequate risk adjustment, plans have incentives to avoid them by "cherry picking" for healthier, white clients. The law's proscriptions against such selection are exceedingly difficult to enforce because plans can do so through such difficult-to-trace means as targeted advertising and patient recruiting.

On the other hand, disadvantaged minority patients are less likely to seek care than are their white counterparts, and they may be less likely to sue their providers. ${ }^{64}$ These propensities could make plans more inclined to seek out subscribers from these groups, tempering the economic unattractiveness of their lower health status. In a study of Medicaid beneficiaries in Florida, Gomes found that capitation payments to managed care plans create greater incentives for plans to serve African Americans and Latinos than Whites. How health plans in fact respond to such incentives has not been empirically documented. Even if plans did respond to such incentives by attempting to "cherry pick" minority patients, reductions in healthcare disparities might not result. Health plans that recruit minority patients because they

61 Bloche, supra note 6, at 108-09.

62 Gianakos, supra note 9, at 1059.

63 See sources cited supra note 46.

64 See UNEQUAL TREATMENT, supra note 1. 
are "cheaper" have little incentive to make these patients more "expensive" by raising the intensity and quality of care these patients receive. ${ }^{65}$ To the extent that improving physician-patient communication through educational programs, translation services, hiring of multilingual physicians and other management strategies might increase minority patients' service utilization, plans have a disincentive to do these things.

In sum, while there are numerous reasons for suspecting that managed care widens healthcare disparities, there is a paucity of empirical evidence bearing on this possibility. Future research should address mechanisms that may differentially affect the intensity and quality of care that managed health plans provide to patients of different ethnic and racial groups. Meanwhile, when weighing alternative cost containment strategies, healthcare policy-makers should pay close attention to how these strategies might aggravate racial and ethnic disparities.

\section{CONCLUSION}

Healthcare disparities are not a large factor in creating health status disparities. But, healthcare disparities not justified by differences in patients' medical conditions, needs and preferences are unacceptable, especially since the health status of disadvantaged racial and ethnic groups in America is incontrovertibly lower than that of Whites. Fairness in healthcare provision across racial and ethnic groups matters not only because medical care influences people's health and well-being, thereby expanding their life possibilities, ${ }^{66}$ it matters because provision of medical care affirms people's belonging to a society ${ }^{67}$ —and their humanity and dignity as community members and citizens.

The account of healthcare disparities that we have advanced here focuses on those disparities that remain after medical insurance status is at least approximately equalized. Whether or not a patient has medical coverage, it should be stressed, is a much more powerful determinant of the healthcare she receives than is her race or ethnicity. Making medical coverage available to all Americans would do more to reduce racial and ethnic disparities in the care Americans receive than would even the most robust effort to ameliorate healthcare disparities among already-insured people. Yet, we believe the latter effort is worth undertaking-and that success in this effort can point the way to a fairer system of universal medical coverage when the nation next attempts to achieve this goal.

Our analysis of the healthcare disparities that remain after insurance status is held constant points to clinical uncertainty as a crucial, underlying factor. Provider uncertainty about the risks and benefits of medical interventions, the content and interpretation of communications from patients, and valuation of the benefits and harms that might arise from medical intervention produces large variations in clinical judgment and practice. Within the scope of accepted variation, clinicians have a great deal of diagnostic and therapeutic discretion. We have argued that race and ethnicity-related stereotypes and biases can-and probably do-influence providers' exercise of this discretion in ways that yield population-wide racial and

65 Carla S. Gomes, Measuring Selection Incentives from Capitation and Risk Adjustment in Florida Medicaid (2002) (unpublished manuscript, Mount Sinai School of Medicine), available at http://www.latino.rcm.upr.edu (last visited Mar. 10, 2003).

66 Norman Daniels, Just Health Care (1985).

67 Michael Walzer, Spheres of Justice: A Defense of Pluralism and Equality (1983). 
ethnic disparities in care. We have also argued that poorer physician-patient communication when patients are members of racial and ethnic minority groups can, in itself, engender disparities by contributing to clinical uncertainty and thereby giving patients and providers rational grounds for doubting the efficacy of medical services.

The central implication of this analysis for health policy-makers is that measures aimed at reducing clinical uncertainty hold out hope for ameliorating racial and ethnic disparities in care. Large-scale clinical outcomes research, efforts to standardize diagnostic and therapeutic judgment when evidence so permits and steps designed to improve provider-patient communication ${ }^{68}$ are among the strategies that should be pursued.

Changes on the horizon in the health sphere could amplify the pernicious effects of medical uncertainty and discretion upon racial and ethnic fairness in healthcare provision. To the extent that managed care's cost control strategies potentiate these effects, the routing of large numbers of Medicaid patients into mandatory managed care will widen racial and ethnic disparities. African Americans, Latinos and other minority groups are disproportionately represented in the Medicaid-eligible population $^{69}$ and thus disproportionately affected by any changes in the Medicaid program. State government finances are now in worse condition than they have been at any time since Medicaid was enacted ${ }^{70}$ and Medicaid is widely perceived, with good reason, as a "budget-busting" program." Pressure on state legislatures and governors to adopt aggressive Medicaid cost-control strategies is greater than ever.

Political and legal pressures on universities to cut back on affirmative action in undergraduate and professional school admissions also threaten to widen healthcare disparities. Minority providers are much more likely to serve predominantly minority patients than are white providers. ${ }^{72}$ Increasing their ranks thus could improve minorities' access to minority physicians without explicit racial and ethnic "matching." Raising the numbers of minority physicians is by no means a cure-all. Providers who share a racial or ethnic identity with their patients may still be very different from them in terms of education, income and experience. Neither race nor ethnicity can, in themselves, create certain rapport. However, empirical studies document higher rates of patient trust, compliance and satisfaction when minority patients are matched with physicians of their own racial or ethnic background. ${ }^{73}$ In addition, were more members of minority groups to attain leadership roles in medical education, they might bring about broader shifts in the ways doctors and other providers understand racial difference.

68 Such measures include support for translation services, hiring of multilingual and multicultural providers, making cultural sensitivity education a standard part of medical training, and provider payment scales that reward time spent speaking and listening to patients. See UNEQUAL TREATMENT, supra note 1 .

69 See id.

70 IRIS J. LAV \& NiChOlas JOHNSON, CTR. ON BUdGET \& POL'y Priorities, STATE Budget DEFICITS FOR FISCAL YEAR 2004 ARE HUGE AND GROWING (2002), available at http://www.cbpp.org (last visited Mar. 10, 2003).

71 VERNON SMITH ET AL., KAISER COMM'N ON MEDICAID \& THE UNINSURED, MEDICAID SPENDING GROWTH: A 50 STATE UPDATE FOR FISCAL YEAR 2003 (2003), available at http://www.kff.org (last visited Mar. 10, 2003).

72 See UNEQUAL TREATMENT, supra note 1.

73 See id. 
Shifting patterns of immigration to the United States could also contribute to the widening of healthcare disparities. New arrivals to America have historically clustered in states such as New York, California and Florida where they have built and sustained social institutions, including healthcare facilities responsive to their special cultural and clinical needs. But, immigrants are increasingly settling in areas that are unaccustomed to their diversity ${ }^{74}$ and that lack healthcare providers and institutions attuned to their needs. The dynamics of clinical uncertainty and provider discretion that we have considered in this Article could engender wider healthcare disparities in these new loci of immigration.

The psychological dynamics and institutional mechanisms that we have inferred and the models we have proposed rest on an incomplete, largely circumstantial evidence base. Creative research is much-needed if we are to better understand the dynamics and mechanisms of racial and ethnic disparity in medical care. That such disparity pervades American medicine is now well-established. The focus of research on healthcare disparities should now shift to these dynamics and mechanisms, and to strategies for amelioration. But, the formulation of policies for reducing disparities should not wait until this research has settled all doubt about dynamics and mechanisms. We have enough of an understanding to craft a variety of strategies for reducing clinical uncertainty, tackling healthcare providers' stereotypes and bias, improving physician-patient communication and constraining clinical discretion. The ongoing wrongfulness of racial and ethnic disparity demands that we act now, as best we can, based on the available evidence. Moral impatience is in order.

74 Steven a. Camarota \& John Keeley, Ctr. for Immigr. Studies, The New Ellis ISLANDS: EXAMINING NON-TRADITIONAL AREAS OF IMMIGRANT SETTLEMENT IN THE 1990S (2001), available at http://www.cis.org (last visited Mar. 10, 2003). 